\title{
Performance of Chemically Treated Natural Fibres and Lime in Soft Soil for the Utilisation as Pile-Supported Earth Platform
}

\author{
Vivi Anggraini $^{1} \cdot$ Afshin Asadi $^{2} \cdot$ Bujang B. K. Huat $^{1} \cdot$ Haslinda Nahazanan $^{1}$
}

Received: 31 May 2015/Accepted: 3 August 2015/Published online: 9 August 2015

(c) Springer International Publishing AG 2015

\begin{abstract}
This work presents the effect of lime and treated coir fibre on the mechanical behaviour of soft clay soil as a pile-supported earth platform. The experimental programme comprised three types of test (flexural strength, indirect tensile strength and triaxial compression strength). Experimental results were used in a numerical analysis in order to observe the performance of the treated soil as a load-transfer base layer depending on the height of the earth platform and the material properties of the treated soil. Two-dimensional physical model experiments were performed to validate the numerical model of the pilesupported load transfer platform. The numerical analyses showed the importance of the mechanical properties of the treated soils for the efficacy and effectiveness of the reduction of the settlement of the earth platform, as well as to enhance the bending performance of the earth platform. The efficacy of limed soil reinforced with chemically treated coir fibres is up to $30 \%$ under various loadings of structures when the effective height of the earth platform is $0.3 \mathrm{~m}$. The differential settlement at the elevation of the pile head is significantly reduced by up to $100 \%$. Present study concluded that this treatment technique can not only increase the mechanical performance of the coir fibres and lime-reinforced soil, but can also improve the interfacial mechanical interactions between the coir fibre surface and
\end{abstract}

Vivi Anggraini

vianggraini@gmail.com

1 Department of Civil Engineering, Faculty of Engineering, Universiti Putra Malaysia, 43400 Serdang, Selangor, Malaysia

2 Housing Research Centre, Department of Civil Engineering, Faculty of Engineering, Universiti Putra Malaysia, 43400 Serdang, Selangor, Malaysia the soil particles, resulting in higher performance of the composites used as a pile-supported earth platform.

Keywords Natural fibre - Lime - Mechanical properties · Numerical analysis · Physical model · Pile-supported earth platform

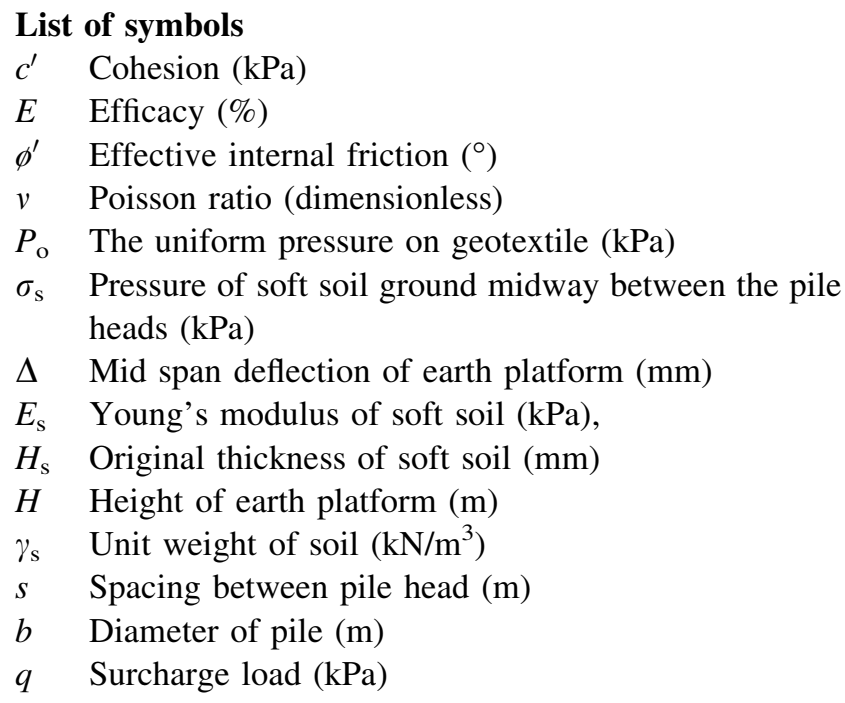

\section{Introduction}

Soft soil improvement by vertical rigid piles permits the reduction and homogenisation of settlements under structures. This process provides an economic and effective solution, especially when rapid construction is required. The areas of application are mainly roadways, railways and industrial building foundations. The most remarkable 
difference of this technique from the deep foundation system is the constitution of an artificial soil layer between the inclusions and the structure. However, piles are not directly connected to the structures. Generally, this soil layer is called an earth platform (EP). Pile-supported earth platform is a technique used to construct embankments or industrial structures on soft soil. The loads are transferred on to the pile head by an arching mechanism in an earth platform located between the piles and the structure in order to reduce the pressure on the soft soil [1].The loadtransfer mechanisms depend on the soil properties and some geometrical parameters, such as the height of the earth platform and the spacing of the vertical rigid piles [2]. The efficiency of the load transfer mechanisms is defined as the ratio of the load supported by rigid piles over the total load applied to the reinforced soil [2-7].

The earth platform can be composed of gravel, ballast, cement soil, cement or another type of cemented soil [2]. Okay and Dias [6] investigated cement and lime-treated soils used under structure foundations in order to homogenise settlements and establish a resistant base layer. Their numerical analysis showed the importance of the strength properties of the treated soils on the efficacy. However, hydraulically stabilised soils are sometimes used to build a transition layer when mineral resources are scarce or costly. Soil treatment with hydraulic binders (i.e. cement or lime) leads to enhanced tensile strength and improved shear resistance over untreated soil; nevertheless, care should be taken to ensure that treated soil retains its ductile behaviour. Brittle behaviour would put the shear mechanisms that operate the load transfer at risk. Realising that soft soil is weak in tension and given the possibility of certain areas of the liner being subjected to flexure, methods of stabilising natural soils use the inclusion of elements capable of resisting forces associated with tension and/or bending [8-12]. Adding fibres can effectively reduce the number and width of shrinkage cracks and help to impede them [8]. Fatahi et al. [13] reported that during shrinkage process, tensile and shear stress will be applied to the soil sample and both fibre and cement contribute to the increase of soil strength and reduction of shrinkage. However, in fibre-reinforced cemented soil, interactions between the fibre surface and the hydrated product had a notable effect on the interface strength $[8,14,15]$. Ziegler et al. [8] found that the adhesion force between the fibre and clay could be raised by increasing the surface area of each fibre by making them wider or longer. In addition, Fatahi et al. [16] found that the fibres increased the residual strength and changed the brittle behaviour of the cementtreated clay to that of a more ductile material.

In this study, the application of randomly distributed chemically treated coir fibre as tensile reinforcement elements with lime in soft soil is investigated for use as a pile- supported load-transfer base layer. Coir is a natural, biodegradable, organic fibre containing cellulose (nearly $44 \%$ ) and lignin (nearly $46 \%$ ). The rate of decomposition of coir fibre is generally known to be less than that of any other natural fibres, such as jute and cotton, owing to the high lignin content. Coir retains $20 \%$ of its strength even after 1 year [17]. Coir is locally available in most parts of south and coastal India, Sri Lanka, the Philippines, Indonesia, Malaysia, Brazil and others. Ramanatha et al. [18] compiled considerable information on the properties of coir fibre and its uses in engineering applications. The use of coir fibres in soft soil is examined in this context and fulfils structural and non-structural requirements for coastal structures.

However, few efforts have been made to enhance the interaction between soil and coir, or the durability of coir fibres by modification of the fibre surface. Therefore, improving the mechanical performance of cellulosic materials of coir fibres using a facile approach attracts many researchers [19-25]. In this study, coir fibres were chemically treated by quick precipitation method. The selected method is simple, effective, inexpensive and technically feasible in the field.

Furthermore, for design, it is necessary to know the stress acting on the soft ground and the pile heads. A simplified numerical study using commercial software (ABAQUS) and theoretical analysis were carried out to understand the load transfer mechanism of treated fibres and lime-treated soft soil as a pile-supported earth platform. In this study, numerical modelling has been developed and experimentally validated to reliably model the behaviour of treated coir fibre-reinforced soil as a pilesupported load transfer platform over soft soil.

\section{Materials and Methods}

Soft clay soil was used as the pile-supported load transfer platform. The physical properties of the soil are tabulated in Table 1. The basic properties of soil, such as grain size, specific gravity and Atterberg limits (liquid limit and plastic limit), were determined according to the British Standard classification tests (BS1377-2). The soft clay was classified as organic clay $(\mathrm{OH})$.

Table 1 Physicomechanical properties of soil sample

\begin{tabular}{ll}
\hline Basic properties & Value \\
\hline Natural moisture content $(\%)$ & 74 \\
Unit weight $\left(\mathrm{kN} / \mathrm{m}^{3}\right)$ & 12.6 \\
Plastic limit $(\%)$ & 42 \\
Liquid limit $(\%)$ & 95 \\
Undrained shear strength $(\mathrm{kPa})$ & 15.6 \\
\hline
\end{tabular}




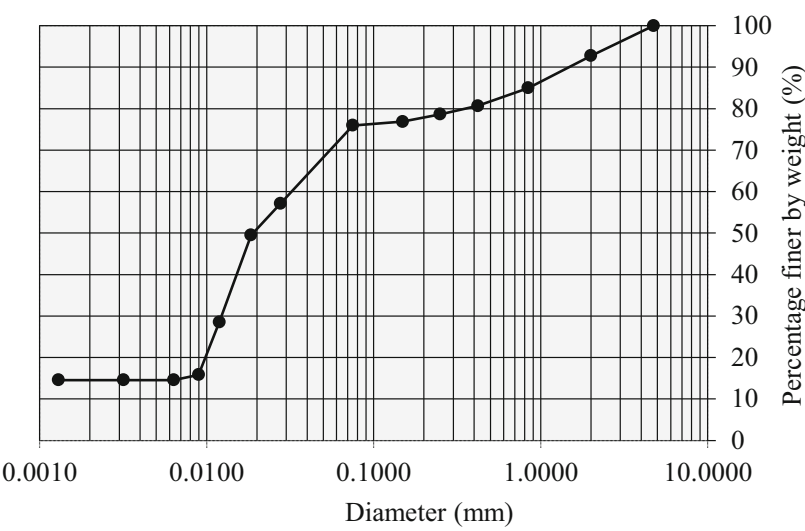

Fig. 1 The grain size distribution curve for soil sample

The grain size distribution curve is shown in Fig. 1, and the maximum dry density and optimum moisture content are $13.5 \mathrm{kN} / \mathrm{m}^{3}$ and $25 \%$, respectively.

A powder-hydrated lime was used as a stabilising material for this study. Coir fibre was used as the fibre reinforcement. They were obtained from a factory in Batu Pahat, South Malaysia. Short discrete coir fibre of $15 \mathrm{~mm}$ in length was used as the reinforcement material. The fibre was pre-treated with $0.5 \mathrm{M} \mathrm{CaCl}_{2}$ in $500 \mathrm{ml}$ aqueous suspension for $24 \mathrm{~h}$. The product was saturated in a beaker covered with aluminium foil. It was kept for $24 \mathrm{~h}$. After $24 \mathrm{~h}$, the treated fibre was washed with $\mathrm{NaOH}$ and dried at room temperature for 4 days prior to casting.

The physicomechanical parameters of the coir fibre provided by the manufacturer are given in Table 2 .

\section{Preparation of Tested Samples}

Two series of soil mixtures, with and without additives, were thoroughly mixed at their optimum moisture content. The mixing of soil with untreated or treated coir fibres was performed manually and then lime was added. The coir fibre has a very good dispersibility. It is easy to mix with soil and obtain a uniform mixture. The mixture for each tested specimen is presented in Table 3.

Three different tests were conducted on the soil specimens in order to determine the effect of treated coir fibres on tensile strength, flexural strength, Young's modulus and shear strength (Table 4). The tests were carried out on three identical samples in order to minimise possible errors due to the material and testing conditions (ASTM D1632-96).

\section{Principle of Soil Improvement by Piles}

The principle of soft soil improvement by vertical rigid piles is presented in Fig. 2. Surface load is transferred to pile heads between the structures and the improved soft soil layer (platform), and a rigid pile grid is constructed into the soft ground layer.

The improvement shown in Fig. 2 is as follows:

- A pile grid is installed through the soft soil layer generally down to a more competent stratum. The rigid piles can be timber piles, metallic piles, concrete piles preformed or cast in place and soil mixing piles. A list of pile types and pile installation techniques is given by Braincon et al. [1]. Pile caps can be added to increase the surface covered by the piles.

- An earth platform placed between the improved ground and the surface structure constituted of treated soil (lime and treated fibre reinforced soil). Shearing occurs in the treated soil owing to differential settlements at the platform base between the soft soil and rigid piles. There is no horizontal reinforcement laid at the platform base (i.e. geosynthetic layers).

- In this improvement technique, the piles are not connected to the substructure. Part of the load is

Table 2 Physicomechanical parameters of coir fibre

\begin{tabular}{|c|c|c|c|c|c|c|c|c|}
\hline $\begin{array}{l}\text { Fibre } \\
\text { type }\end{array}$ & $\begin{array}{l}\text { Length } \\
(\mathrm{cm})\end{array}$ & $\begin{array}{l}\text { Diameter } \\
(\mathrm{mm})\end{array}$ & $\begin{array}{l}\text { Density } \\
\left(\mathrm{kN} / \mathrm{m}^{3}\right)\end{array}$ & $\begin{array}{l}\text { Breaking tensile } \\
\text { strength (MPa) }\end{array}$ & $\begin{array}{l}\text { Modulus of } \\
\text { elasticity (MPa) }\end{array}$ & $\begin{array}{l}\text { Fusion } \\
\text { point }\left({ }^{\circ} \mathrm{C}\right)\end{array}$ & $\begin{array}{l}\text { Acid and alkali } \\
\text { resistance }\end{array}$ & Dispersibility \\
\hline $\begin{array}{l}\text { Single } \\
\text { fibre }\end{array}$ & $13-15$ & $0.2-0.3$ & 14.0 & 140 & 60 & 135 & Good & Very good \\
\hline
\end{tabular}

Table 3 Mixture of the tested materials and optimum proctor values

\begin{tabular}{llllc}
\hline Mixture & Fibre (\%) & Lime (\%) & $\begin{array}{l}\text { Moisture } \\
\text { content }(\%)\end{array}$ & $\begin{array}{l}\text { Dry density } \\
\left(\mathrm{kN} / \mathrm{m}^{3}\right)\end{array}$ \\
\hline Soil (S) & 0 & 0 & 25 & 13.5 \\
Soil + lime (SL) & 1 & 5 & 26.8 & 12.8 \\
Soil + lime + non-treated fibre (SLF) & 1 & 5 & 27.3 & 12.7 \\
Soil + lime + treated Fibre (SLCF) & 1 & 5 & 28.2 & 12.5 \\
\hline
\end{tabular}


Table 4 Testing procedure

\begin{tabular}{llllr}
\hline Test type & $\begin{array}{l}\text { Testing } \\
\text { procedure }\end{array}$ & $\begin{array}{l}\text { Loading rate } \\
(\mathrm{mm} / \mathrm{min})\end{array}$ & \multicolumn{2}{l}{ Size of specimens $(\mathrm{mm})$} \\
\cline { 5 - 5 } & ASTM D1635 & 1 & 50 & Height \\
\hline FS & Brazilian tension test & 1 & 50 & 100 \\
ITS & ASTM D4767-04 & 1 & 50 & 50 \\
TCS & &
\end{tabular}

FS Flexural Strength, ITS Indirect Tensile Strength, TCS Triaxial Compression Strength (Confining stresses: 50, 100 and $150 \mathrm{kPa}$ )

Fig. 2 Schematic section of treated soil platform supported by piles in soft soil and the improvement principle

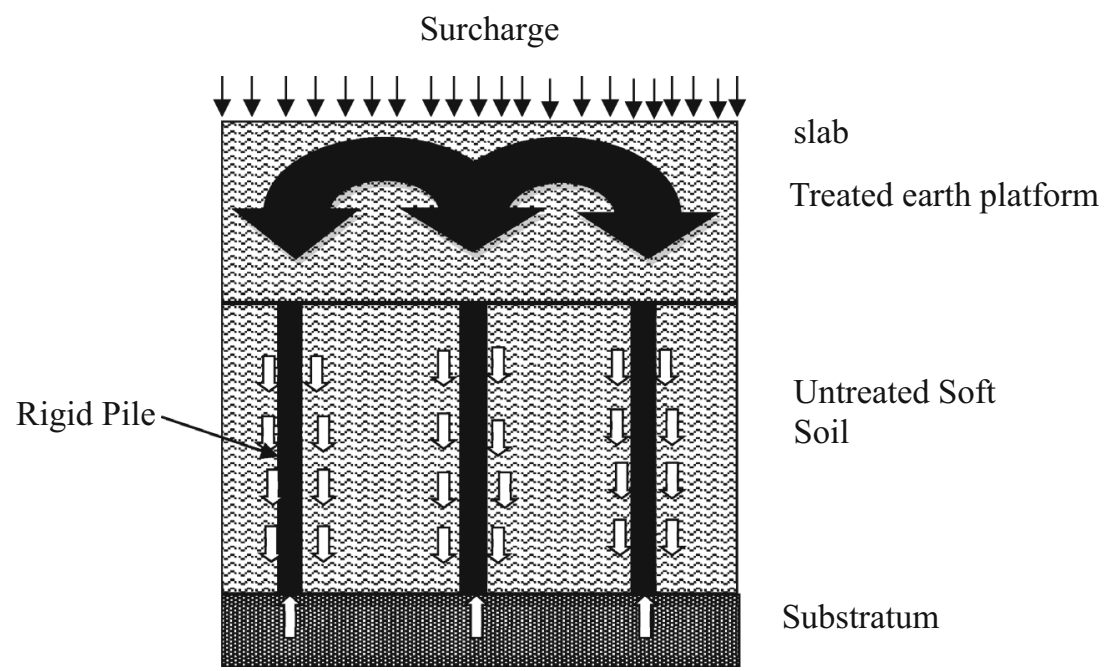

transferred onto the piles by stress concentration ratio. For the design, it is necessary to determine the stress acting on the piles. Static equilibrium of vaults elements permits calculation of the efficacy $(E)$, defined as the proportion of the mat/platform weight carried by the piles [3]. This may be expresses as:

$E=1-\frac{(s-b) \sigma_{\mathrm{s}}}{s\left(\gamma_{\mathrm{s}} H+q\right)}$

\section{Pysical Modelling}

A two-dimensional model test of a pile-supported earth platform over soft subsoil was developed to study the load transfer and settlement reduction mechanisms occurring in this part of the system.

A diagram of the model test is given in Fig. 3. The model is $800 \mathrm{~mm}$ wide, $400 \mathrm{~mm}$ long and $300 \mathrm{~mm}$ high. The unit weight of this material was determined as $16 \mathrm{kN} /$ $\mathrm{m}^{3}$. The soft soil is simulated by $100-\mathrm{mm}$ thick untreated soft soil. These elements aim at simulating a real subsoil layer and settlements at the platform base are obtained. The effect of the soft subsoil is rarely taken into account, whereas the mechanisms developing above the piles and in the soft subsoil are connected [26]. By placing sand in alternate colour layers, the platform settlement was observed under maximum applied load. Four load transfer transducers are placed on the platform, which permits quantifications of the differential settlement occurs between the rigid piles and the soft soil.

Two units of circular steel bar are used to represent the piles, which are fixed to the rigid apparatus frame to avoid any vertical and lateral displacements of the piles. The mechanisms at the central zone of the earth platform between two piles assume that no boundary effect is observed.

The platform is set up as a $0.05 \mathrm{~m}$ thick layer. A $112.5 \mathrm{kPa}$ surcharge application constituted by the actuator is then placed at the surface. The settlements were recorded at each $6.25 \mathrm{kPa}$ surcharge increments. The developed model presents modularity in terms of geometrical parameters.

\section{Interest and Limitations of the Model}

This model was developed because it presents numerous advantages in relation to our research objectives:

- Measurements are possible in terms of both loads and displacements, which allows simultaneous study of the load transfer onto the piles and the settlement reduction 
Fig. 3 Test setup and instrumentation detail of the physical model of an earth platform

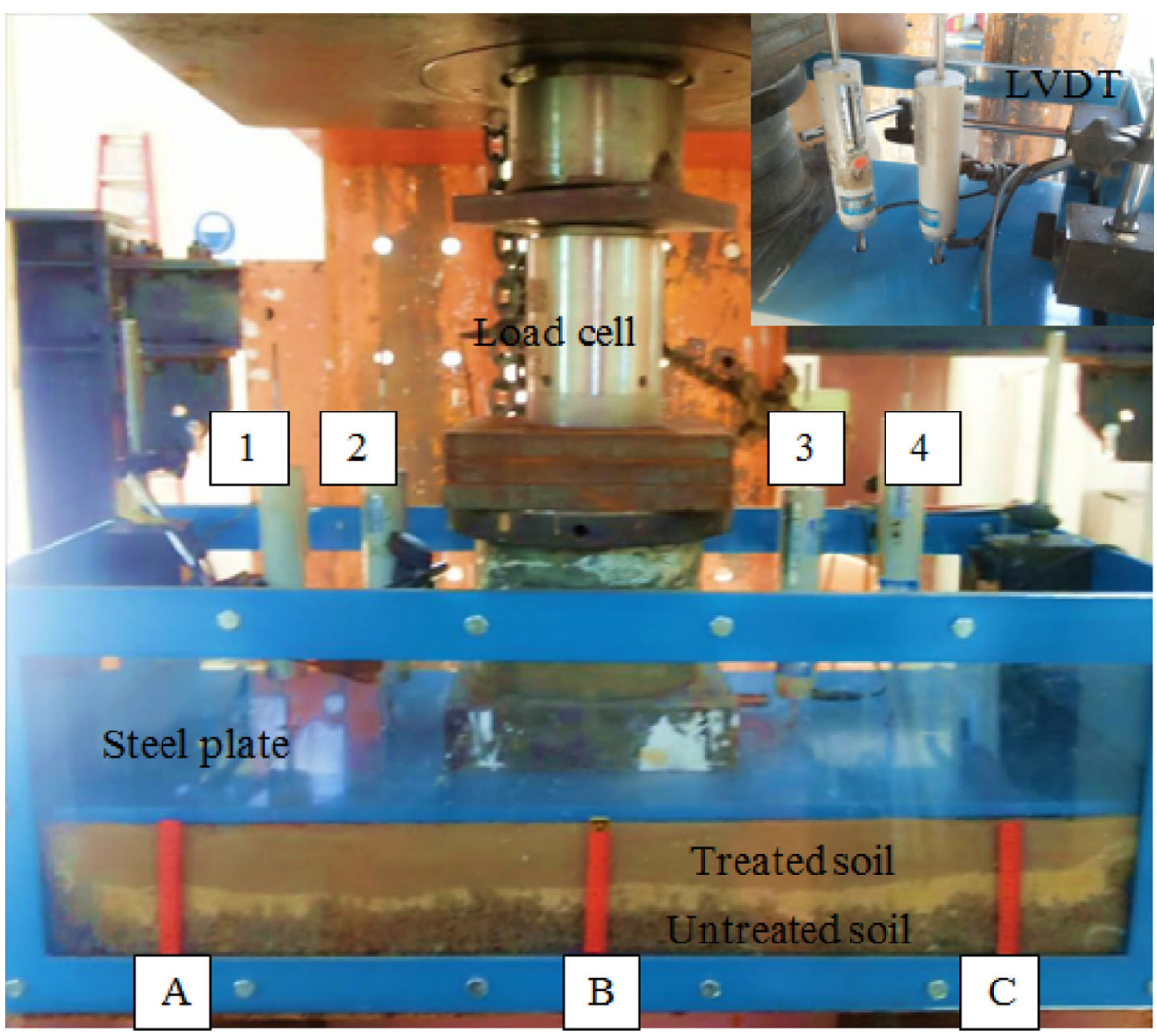

in the platform, thus offering a strong comparison to numerical models in order to validate the numerical procedure.

- The model presents a high modularity, which allows several parametric studies to be conducted.

- The soft soil simulated a real subsoil layer and settlements at the platform base are obtained.

However, this physical model presents limitations, which are as follows:

- The model proposed is a simplification of the reality, as it considers a two-dimensional case whereas this type of system is typically three dimensional.

- The similarity rules are not strictly respected. However, this physical model does not aim at simulating the behaviour of a real system but it is used to understand the efficacy of an earth platform in order to determine the effectiveness of reinforcement in reducing settlement and enhance bending performance.

- The aim of this study is to observe the behaviour of the earth platform; the behaviour of the soft soil below the earth platform was not taken into account (i.e. bending, end bearing and friction of pile). The length of the pile was not considered, it is used as a support in order to study the flexural behaviour of the earth platform.

- In this model, geometric scaling was adopted. Settlement beneath the earth platform induced by the
$112.5 \mathrm{kPa}$ surcharge application was measured. However, the total force applied will have the same value for the prototype and the scaled down model when the geometry is reduced.

- Platform material properties cannot be varied in the smallscale model. Hence, cohesion, friction angle, Young's modulus and Poisson's ratio were not scaled down.

- In this model, the earth platform height is generally limited and is not enough to develop an arching mechanism.

\section{Simplified Numerical Model}

Numerical modelling is a powerful tool to extend the study of the mechanisms occurring in this type of foundation system, but models first have to be validated on experimental results. In this study, the numerical modelling of lime and treated coir fibre-reinforced soil as a load-transfer base layer was performed using ABAQUS CAE 6.11. Real geometry and properties for the constitutive materials are used in the numerical model. Particular attention was paid to the influence of the mechanical properties of treated soil on the efficacy of the soil reinforcement.

To simplify the analysis, each single pile is considered as having an "effective" equivalent circle (or cylindrical in a three dimensional view) with the area shown in Fig. 4. 
Fig. 4 Schema of the simulated zone and mesh distribution

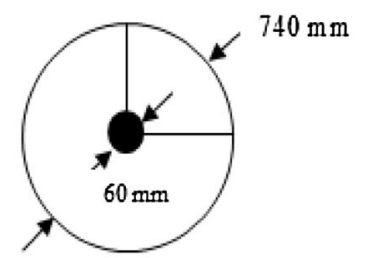

(a) Plan view

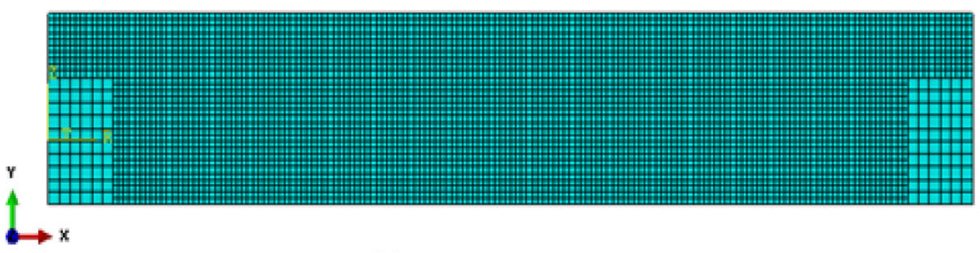

(b) Mesh distributions

Surcharge load $(q)$

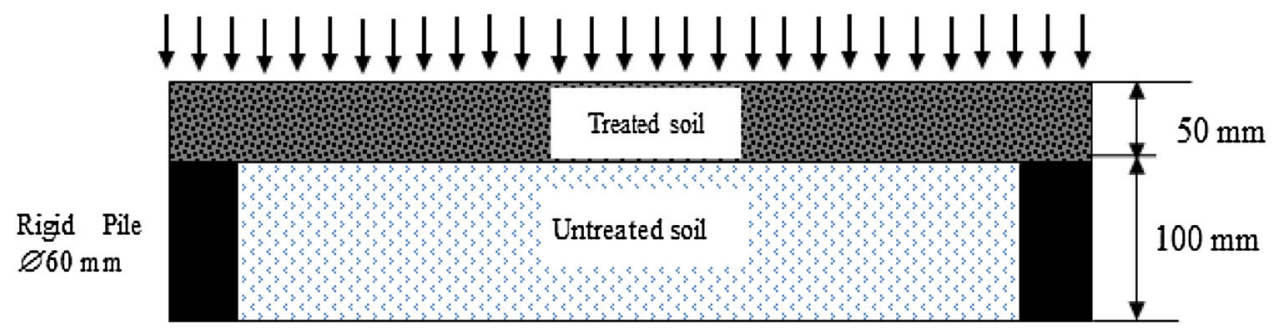

(c) Analysis of the settlements due to surcharge

The review of the constructed treated soil as piled load transfer base layer indicated the typicalpile spacing used in these projects range from 1 to $4.5 \mathrm{~m}$ [27].

A pile with a typical diameter of $300 \mathrm{~mm}$ is selected to be used in ground improvement. The pile length and spacing of 500 and $3700 \mathrm{~mm}$, respectively, is selected for developing the model. Scaling down of the model to $20 \%$ is done for numerical and experimental purposes. Therefore, the pile diameter, length and spacing will be 60,100 and $740 \mathrm{~mm}$, respectively. An average influence diameter of $740 \mathrm{~mm}$, which is the same as the pile spacing, is selected in this study. The pile and soft soil were assumed to be above a very stiff layer, such as bedrock, thus no deformation is assumed below the pile and soft soil. In fact, for a scale reduction approximately equal to five, the stress level is maintained. The scale reduction factor lies in a range between three and seven, which was also used by Jenk et al. [26] to develop a small-scale model test of a pile-supported earth platform. Since there are limitations of scaling rule in this study, this model permits a precise analysis of the influence of parameters on load transfer mechanisms and permits the development of a database for future numerical analysis.

Clay characteristics $[28,29]$ were attributed to the compressible layers. The horizontal earth pressure coefficient at rest, $K_{0}$, was considered equal to 0.5 for compressible soil layers. In practice, foundations are set up just after the treatment of the soil. Nevertheless, the loads are applied more lately. For this reason, in the numerical calculations, the properties of the treated soils at 90 days of curing after the treatment were used. A linear elastic perfectly plastic constitutive model using Mohr-Coulomb failure criterion was used to simulate treated soils.

The model requires the following input parameters: Young's modulus, Poisson's ratio, cohesion and angle of internal friction. The properties of the treated soils for the simulation are summarised in Table 5.

The pile was considered to have a linear elastic behaviour. The pile is connected to the soil via interface elements that follow Coulomb's law. The piles and the soil layers were set up in only one phase, which constitutes the initial state. The effect of pile installation was thus not taken into account. The soil and the pile are represented by volume elements [6].

The term efficacy was used in order to determine the effectiveness of reinforcement [4-6, 30-33]. Efficacy is the ratio between the load transmitted to the head of the pile and the total load on the unit grid. The following numerical calculations were analysed in terms of efficacy. 
Table 5 Model parameters of the unreinforced and reinforced soils

\begin{tabular}{|c|c|c|c|c|c|c|c|}
\hline & & & $S$ & SL & SLF & SLCF & $\begin{array}{l}\text { Type } \\
\text { of test }\end{array}$ \\
\hline Young's modulus & $E_{s}$ & MPa & 13 & 29 & 39 & 51 & FS \\
\hline Effective angle of friction & $\phi^{\prime}$ & & 25 & 28 & 40 & 42 & TCS \\
\hline Poisson ratio & $v$ & - & 0.303 & 0.310 & 0.296 & 0.317 & ITS \\
\hline Cohesion & $c^{\prime}$ & $\mathrm{kPa}$ & 5 & 9 & 40 & 75 & TCS \\
\hline
\end{tabular}

FS Flexural strength, ITS Indirect tensile strength, TCS Triaxial Compression strength (a)

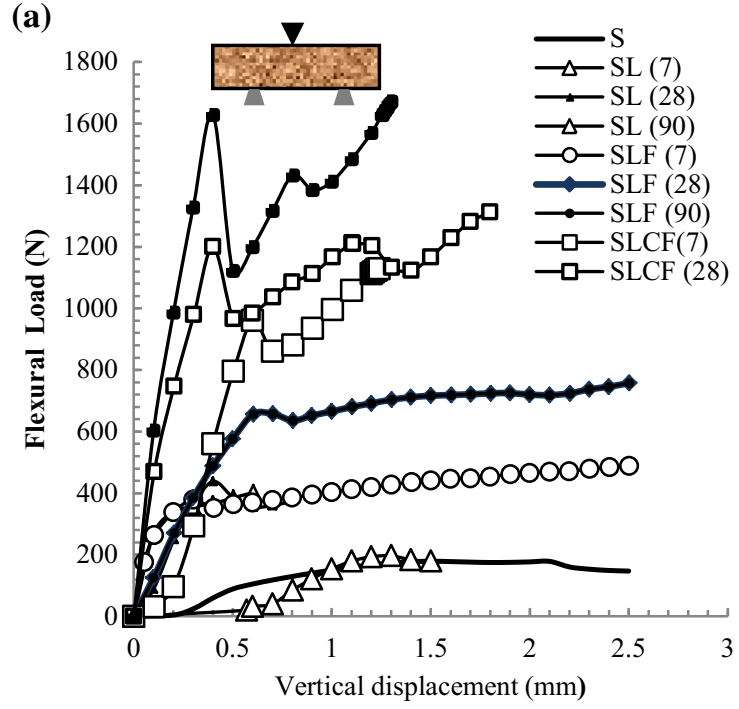

(b)

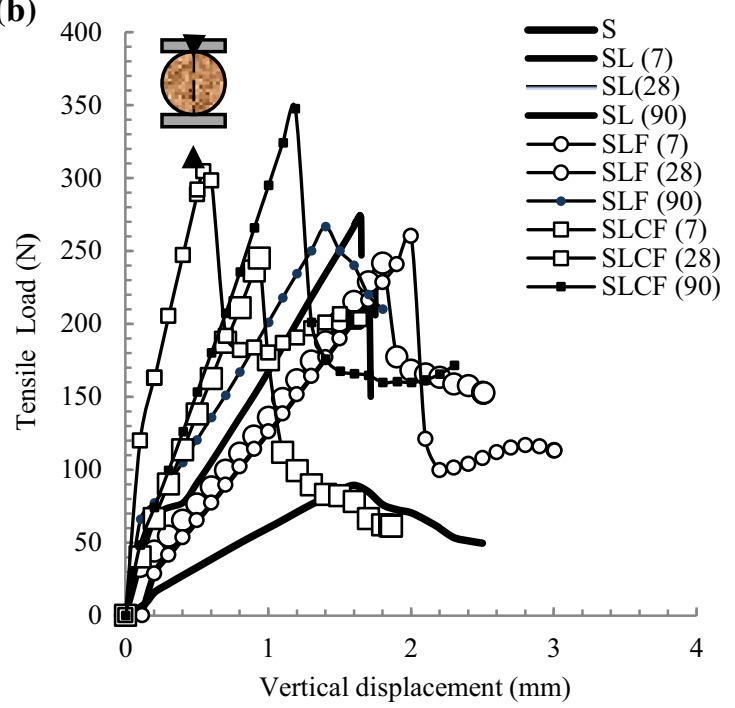

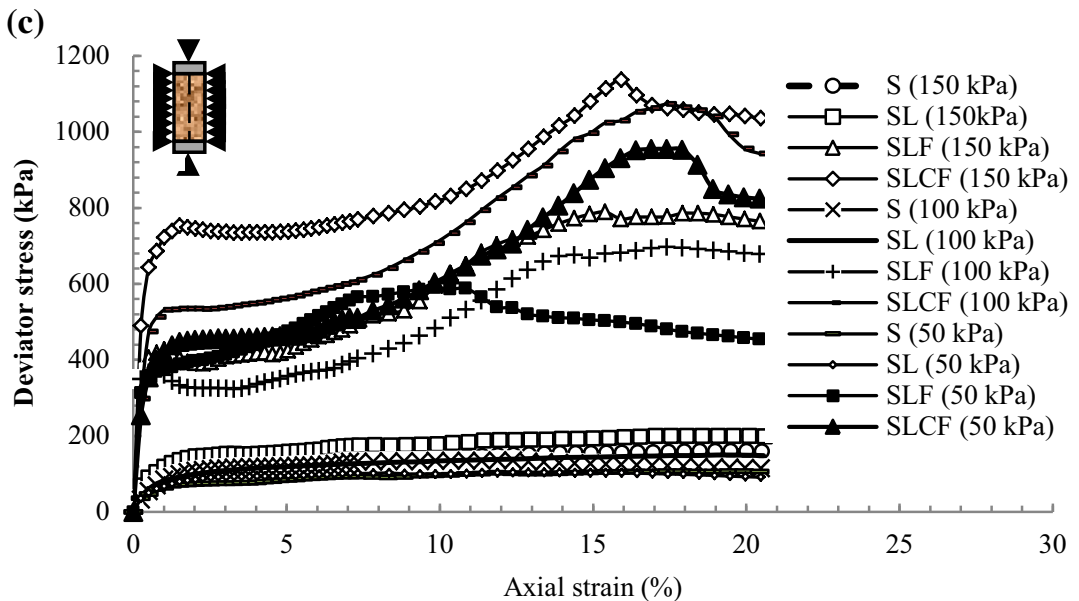

Fig. 5 Stress-strain or load-displacement curves for: a Flexural strength (FS) test b Indirect tensile strength (ITS) test and c Triaxial compression strength (TCS) test

\section{Results and Discussion}

\section{Mechanical Performance of Coir Fibres and Lime- Treated Soil}

Figure 5a-c show the effect of the lime with untreated and treated fibres at various curing ages, in terms of the stress- strain or load-displacement behaviour evaluated from Indirect tensile strength (ITS), Flexural strength (FS) and Triaxial compression strength (TCS) tests. The results from FS (Fig. 5a) and TCS (Fig. 5c) are consistent with each other and illustrate the significant impact of the addition of treated coir fibre to the limed soil in terms of load-displacement (ITS and FS). In general, the inclusion of fibres 
changes the behaviour from a brittle to a ductile behaviour compared to untreated soil and lime-treated soil ( $\mathrm{S}$ and $\mathrm{SL}$ ). However, the inclusion of treated fibres in stabilised soil significantly increased the peak of strength without an apparent loss of strength after peak, which is a consequence of the mobilisation of the tensile strength of the treated fibres at higher deformations, as illustrated in Fig. 5a. With further loading, the reinforced layer in the tension zone became fully activated and the load continued to increase at large deflections without any signs of failure. The interfacial friction and bonding between the contact area of the soil particles and the fibres may aid in the load transfer and contributed to an increase in tensile resistance of the fibre-reinforced soil (Fig. 5a).

The load-displacement behaviour from ITS test (Fig. 5b) was not equal to that observed in the remaining tests, since the stiffness is not affected by the presence of fibres; both with untreated and treated fibres continue to be brittle, although the loss of strength after peak is lower with the inclusion of fibres. After failure, the residual strength observed is due to the mobilisation of the tensile strength of the fibres.

Figure 5c shows the stress-strain relationship of the samples at various confining pressures. As can be seen from the figure, the treated fibre-reinforced soil specimens had higher peaks than the untreated fibre-reinforced soil specimens for all the confining pressures. Furthermore, the post-peak behaviour of the fibre-reinforced soil showed that fibres were effective enough to mobilise operative tensile stress in the samples. As can be seen from the figure, the results of the shear tests on treated samples showed that fibres obstructed the induced cracks more effectively after failure. The treated fibres mixture had the highest peak response of all samples. The maximum values of deviator stress significantly increased to about 438, 531 and $780 \mathrm{kPa}$ at confining pressures of 50,100 and $150 \mathrm{kPa}$, respectively, for treated fibre samples. The enhancement was 15,78 and $86 \%$ compared with the untreated fibre reinforced soil specimens. The results showed that the

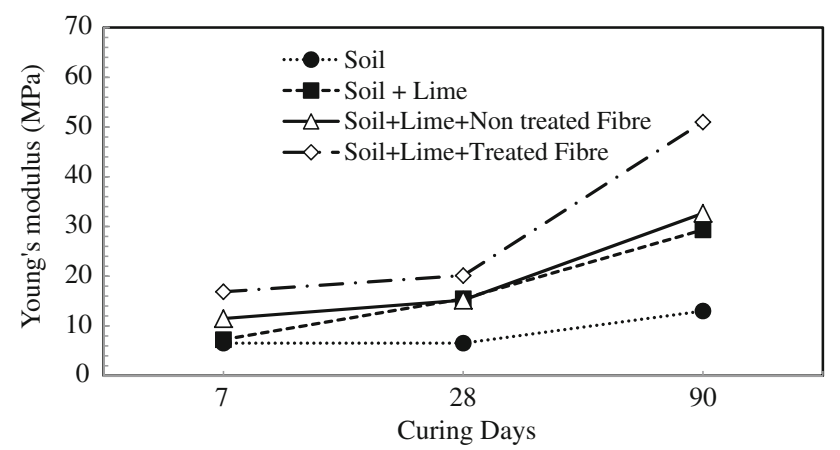

Fig. 6 Evolution of Young's modulus stress-strain behaviour was markedly affected by incorporating treated fibres into the soil. The inclusion of treated fibres caused an increase in peak shear strength and a reduction in the loss of post-peak stress for all different confining stresses. This behaviour may be attributable to strong interfacial adherence and frictional interaction between the treated fibres and the soil particles.

In terms of stiffness, the inclusion of both untreated and treated fibres promotes the increment in the Young's modulus $\left(E_{\mathrm{s}}\right)$. The Young's modulus evaluated from the three-point bending tests may represent the behaviour of the earth platform under surface load. Figure 6 shows the evolution of the Young's modulus for untreated and treated coir fibre-reinforced soil at various curing periods. The highest values of Young's modulus were obtained in treated fibre samples. The enhancement in Young's modulus obtained from bending tests was 33, 32 and $55 \%$ for 7, 28 and 90 days of curing, respectively. The maximum Young's modulus in treated fibre samples was $51 \mathrm{MPa}$ at 90 days of curing. It was revealed that inclusion of impregnated fibres treated with chemical resulted in sufficient bonds in the interaction zone between limed soil and fibres permitting load to transfer through shear when samples were loaded.

Indirect tensile strength tests permitted the calculation of Poisson's ratio of treated soils using techniques based on the theory of elasticity (Fig. 7). Different treatment in the limed soil with untreated and treated fibre leads to variations in the value of the Poisson's ratio from 0.296 to 0.317. Changing the Poisson's ratio, it is expected that significant changes will emerge in soil resistance of fibre inclusion in limed soil. The highest value was 0.317 for treated fibre-reinforced limed soil. It indicates the greater plasticity of the composites.

The Mohr circles of failure at different effective confining stresses together with the failure envelopes for all samples are shown in Fig. 8a-d. As can be seen, the fibrereinforced soil showed a significant apparent cohesion and friction angles. The values of the cohesion were $5 \mathrm{kPa}$ for

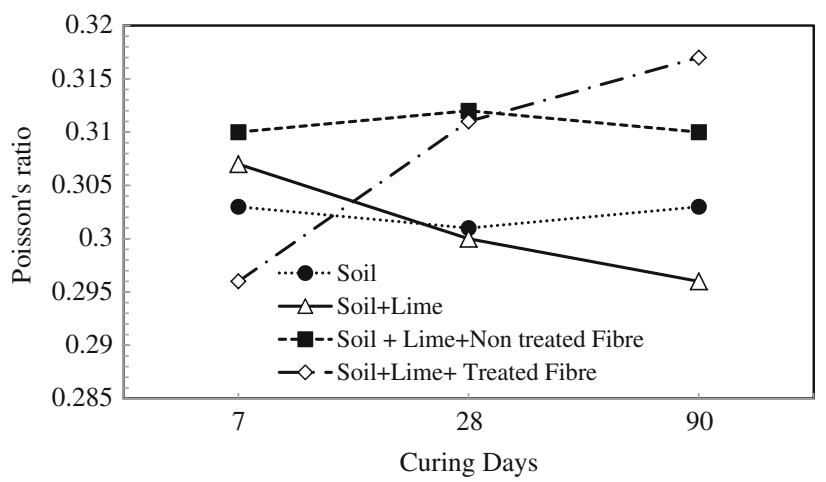

Fig. 7 Evolution of Poisson's ratio 
soil (S), $9 \mathrm{kPa}$ for soil and lime (SL), $40 \mathrm{kPa}$ for untreated coir fibre- (SLF) and $75 \mathrm{kPa}$ for treated fibre-reinforced limed soil (SLCF). The values of internal friction angles

(a)

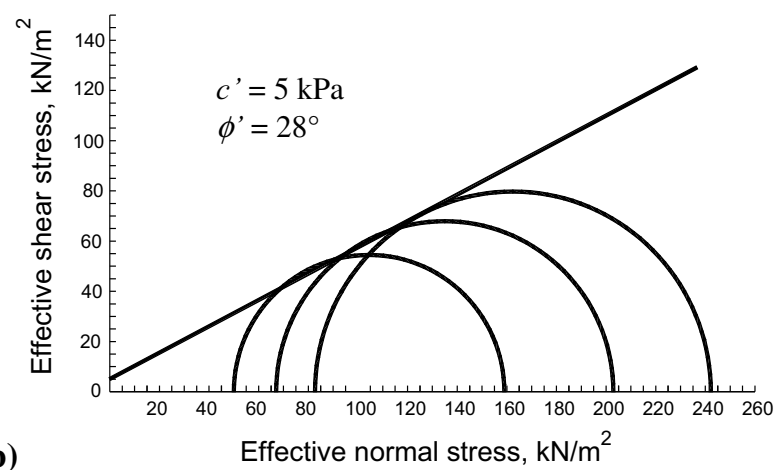

(b)

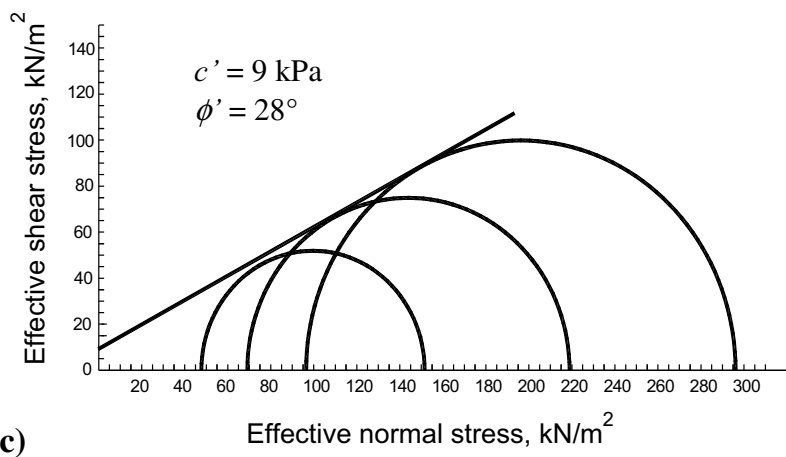

(c)

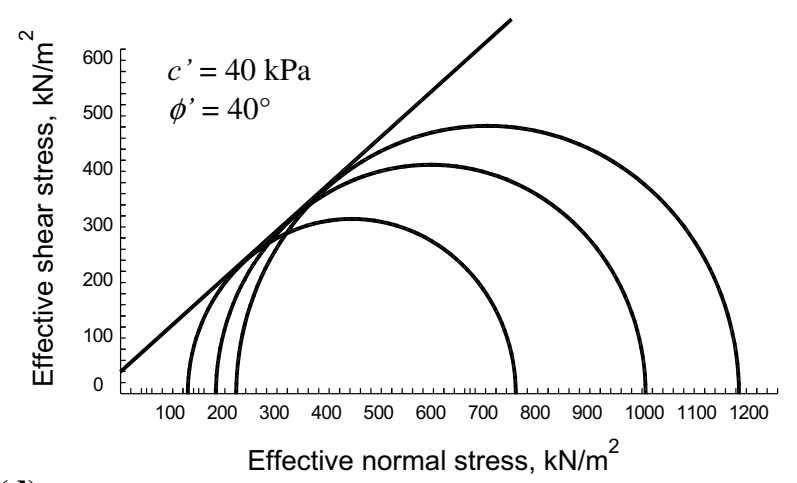

(d)

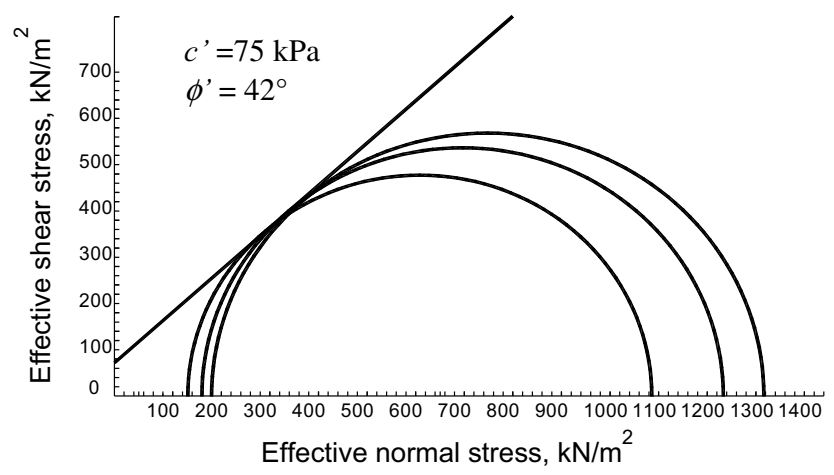

Fig. 8 Mohr circles of untreated and treated soil: a S, b SL, c SLF and d SLCF were $25^{\circ}$ for natural soil, $28^{\circ}$ for lime soil, $40^{\circ}$ for untreated fibre- and $42^{\circ}$ for treated fibres-reinforced limed soil. It is believed that significant tensile strength can be developed along the length of untreated coir fibres. However, treated coir fibre increases the cohesion and internal friction angle of soil better than untreated coir fibre.

However, degradation of cemented soil should be considered for a treated platform under structural load. Nguyen et al. [34] developed a constitutive model for cemented clays by simulating the cementation degradation during loading. The effects of cementation degradation can be observed when the sample undergoes isotropic consolidation in the triaxial test. The authors found that the effective confining pressure plays a dominant role in the behaviour of cemented clays. The effect of cementation is diminished as the effective confining pressure is increased owing to degradation of cement-soil particle bonding.

\section{Comparison Between Experimental and Finite Element Analysis (FEA)}

In order to analyse the displacement field in the platform, the case of $31.25,62.5,93.75$ and $112.5 \mathrm{kPa}$ surcharge application is considered. The settlements caused by this loading stage are analysed along a vertical line above the pile and along a vertical line among both piles, as illustrated by Fig. 9 .

Figure 9 show physical modelling of the settlement due to surcharge load. The settlement at the base of the earth platform (EP) during the experiment was simulated by placing a steel plate above the EP to ensure that the load can be distributed uniformly. The uniform load was considered as surcharge load that comes from the upper structure. Load is transferred to the pile as a result of the negative skin friction that develops wherever soft soil settles more than piles. The negative skin friction is beneficial because it helps in transferring loads. As can be seen from Fig. 9, settlement of $20 \mathrm{~mm}$ occurs at the midpoint of the soft soil while the minimum settlement is $1.5 \mathrm{~mm}$ at above the pile heads.

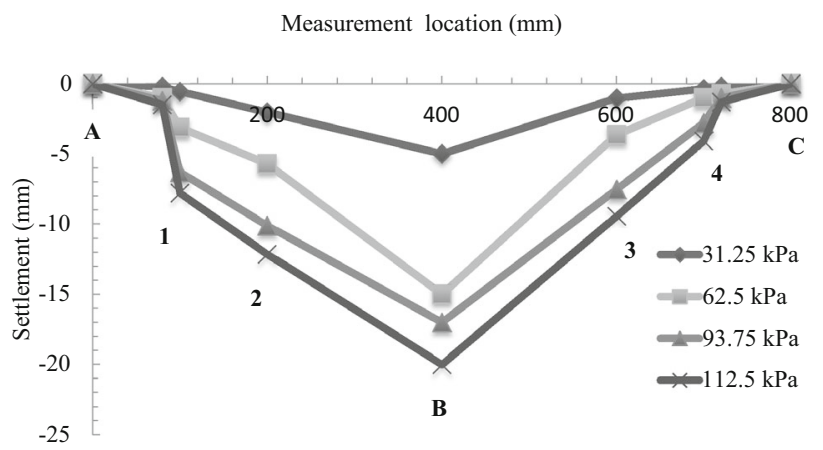

Fig. 9 Experimental observation of the settlements due to surcharge 


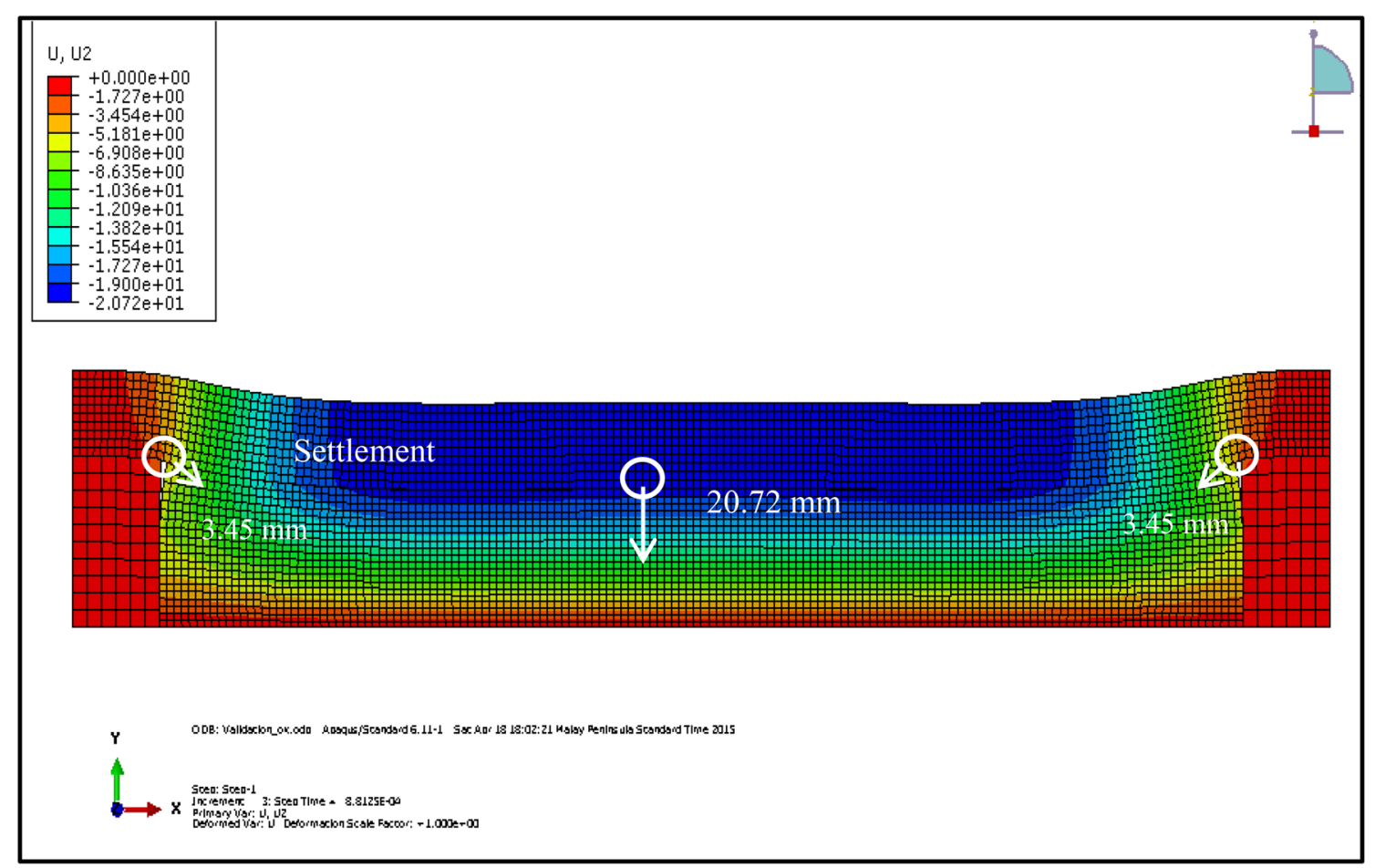

Fig. 10 FEA of the settlements due to surcharge

The numerical modelling results are compared in terms of settlements, which demonstrated the effectiveness of reinforcement of the earth platform. Figure 10 presents FEA of settlement of soils at midway between pile heads and above the pile heads due to the surcharge load. It can be observed that maximum settlement of $20.72 \mathrm{~mm}$ occurred at the midpoint of the soft soil while the minimum settlement of $3.45 \mathrm{~mm}$ takes place above the piles. The settlement pattern and results of FEA show good agreement with the experimental results.

\section{Parametric Studies}

The results of the parametric studies are presented and analysed in terms of:

- Settlement induced by various surcharge applications at the top of earth platform of the several heights of earth platform.

- Maximum efficacy, obtained at the end of the loading stages, to assess the load transfer onto the piles.

- Bending and shear resistance of the material used as the load transfer layer.

\section{Settlement}

Figure 11 shows the influence of the height of the EP on the settlement of the soft soil. It can be observed that

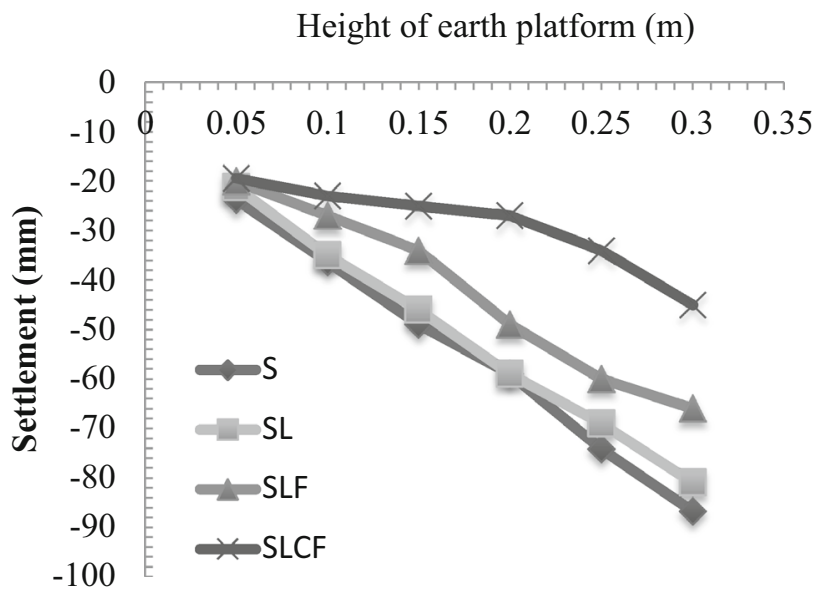

Fig. 11 Effect of height of earth platform on settlement from surcharge load

settlement was increased when the height of the platform increased. This indicates that the differential settlement at the elevation of the pile head is significantly reduced by an increase of the internal friction and elastic modulus of the treated soil; the highest reduction was for SLCF following by SLF.

Soil reinforcement is performed to reduce settlements and increase the bearing capacity of soil.. Soil reinforcement increased the bearing capacity of soil and it was crucial to the deformation of structures. The differential 
settlement was measured from centre of pile to centre of piles spacing $(\mathrm{s}=3.7 \mathrm{~m})$ with $1.85 \mathrm{~m}$ distance from pile head. The distance is considered due to the fact that it permits the maximum differential settlement to be obtained. This value is important for the development of the load transfer mechanism in the earth platform [6].

Figure 12 shows the results of the numerical study, which demonstrated that inclusion of randomly distributed treated fibres as a load transfer base layer reduced the differential settlements above the pile heads and at the ground surfaces, and promoted efficient load transfer from the soil to the piles. As can be seen from the figure, the differential settlement at the elevation of the pile head was significantly reduced by an increase in the tensile stiffness of $\mathrm{CaCl}_{2}$ treated fibres (SLCF). It was reduced by $40 \%$ compared to untreated soil (S) and followed by $29 \%$ for untreated fibre-reinforced soil (SLF). The differential settlements at the ground surface and at the elevation of the pile head decrease with an increase of the internal friction angle of the treated soil. In the case with platform improvement, the settlement is equal to $0.02 \mathrm{~m}$ with a platform height of $0.05 \mathrm{~m}$. The use of compacted natural soil as a load-transfer base layer does not prevent settlement of the soil. It was clearly seen from the figure, that the settlement was $0.032 \mathrm{~m}$.

\section{Vertical Stress}

To better analyse the load transfer mechanisms that occur in the platform material, the stress field in the numerical model is studied.

Figure 13 shows the variation of vertical stress on soft soil ground midway between pile heads versus height of earth platform. At surcharge loading, as the earth platform increases, the vertical stress also increased. Untreated soil

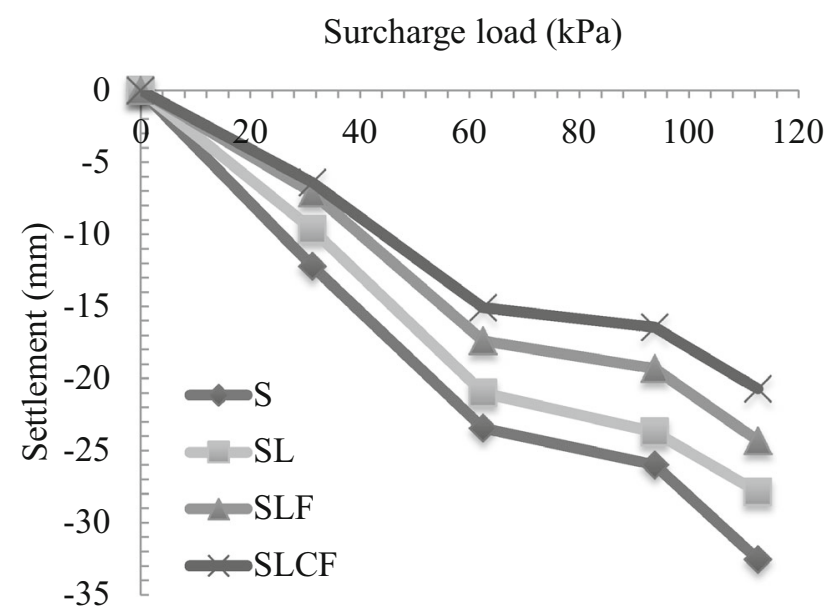

Fig. 12 Effect of the earth platform's mechanical properties on settlement at various surcharge loads of the earth platform's height of $0.05 \mathrm{~m}$

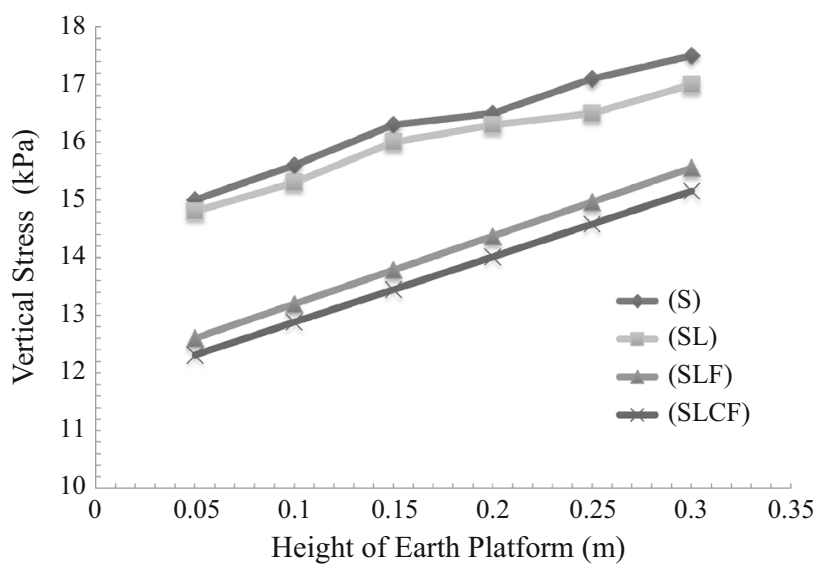

Fig. 13 The vertical stress on soft soil ground midway between the pile heads for various earth platform materials

(S) with an earth platform height of $0.05 \mathrm{~m}$ contributed a vertical stress of $17.5 \mathrm{kN} / \mathrm{m}^{2}$, while treated fibre reinforced limed soil (SLCF) contributed a vertical stress of $15.15 \mathrm{kN} / \mathrm{m}^{2}$ on soft soil ground midway between pile heads. SL and SLF contributed vertical stress of 17 and $15.5 \mathrm{kN} / \mathrm{m}^{2}$, respectively. It can be observed that SLCF contributed the lowest stress on soft soil ground midway between pile heads among them.

\section{Efficacy}

In this study, the platform material was constituted of materials treated with lime and chemically treated fibres, which introduce cohesion in the soil [35]. The influence of the platform materials' cohesion is investigated. As the stress level in the model is more or less maintained, the scale factor on the cohesion is close to one [26]. The numerical models confirm that the efficacy increases when the height of platform is increased [3, 26, 28, 36].

Figure 14 compares the efficacy of each treated soil as an earth platform material. As the height of earth platform increases, the efficacy increases whereas the highest

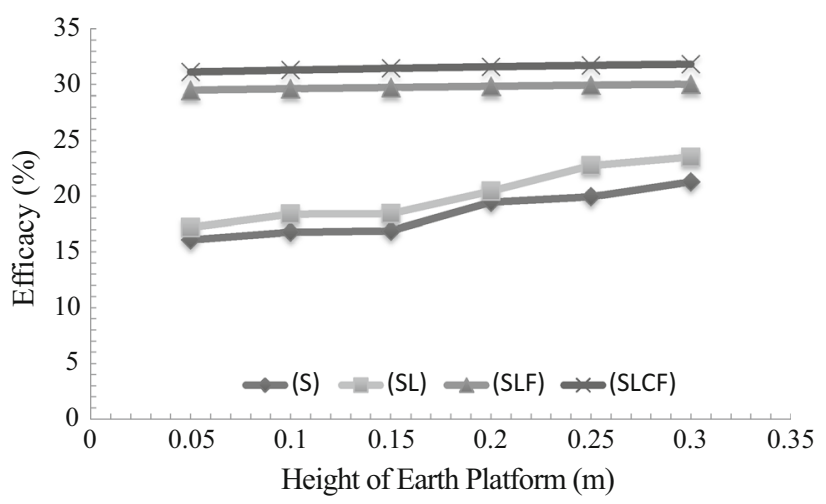

Fig. 14 Performance of the material characteristics on the efficacy 
Fig. 15 The vertical stress on soft soil ground midway between the pile heads at $0.05 \mathrm{~m}$ height of earth platform
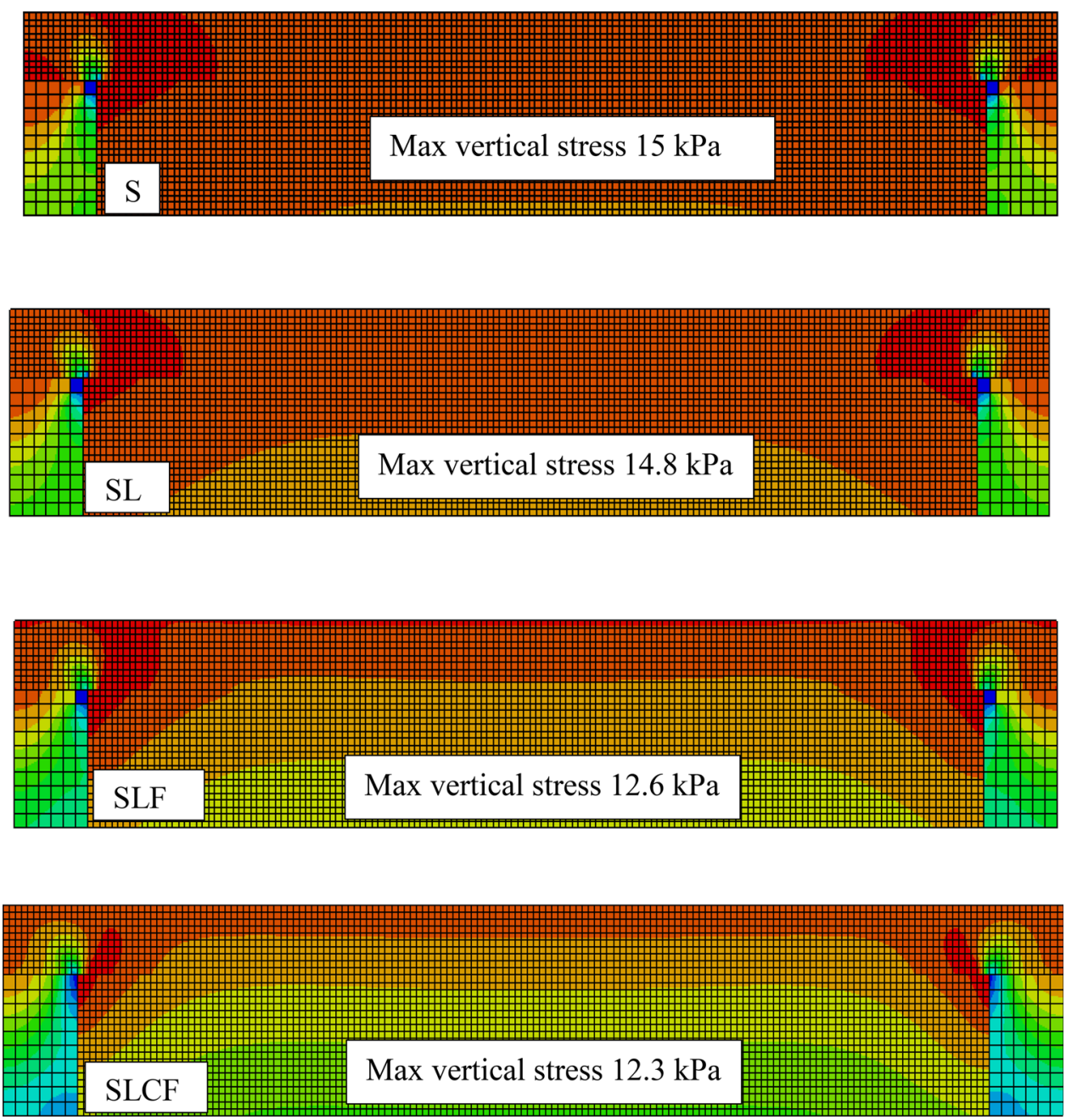

value was from SLCF due to having superlative strength characteristics. The efficacy of untreated soil (S) with $\phi^{\prime}=25^{\circ}$ and $c^{\prime}=5 \mathrm{kPa}$ and was $21 \%$ under various heights of earth platform, while the highest efficacy is $32 \%$ for the SLCF platform type with $\phi^{\prime}=42^{\circ}$ and $c^{\prime}=75 \mathrm{kPa}$. It means that untreated soil transmitted more than $79 \%$ into the compressible layer, while SLCF transmitted less than $68 \%$ load into the compressible layer (soft soil). It can be observed that the internal friction plays an important role in transferring load from the surface of the earth platform to the pile head. However, it can be observed that SLF transfers loads more to pile heads if compared to SL. It is due to the SLF having a better internal friction angle than SL. It can be observed that more stresses are transferred to the pile head for SLCF rather than the S soil type (Fig. 15). The more influential geotechnical parameters are the platform shear strength characteristics (friction angle $\phi^{\prime}$ and cohesion $c^{\prime}$ ), which strongly influence both the load transfer onto the pile and settlement [26].

\section{Bending Performance of Earth Platform}

In this study, particular attention was paid to the bending resistance of the material used as the load transfer layer. In order to observe the effectiveness of the reinforcement on the earth platform, numerical calculations were performed with the EP height of $0.05 \mathrm{~m}$. Low et al. [5] proposed correlation between the stress of soft soil and the mid-span deflection of an earth platform as follows:

$P_{\mathrm{o}}=\left(\sigma_{\mathrm{s}}-\frac{E_{\mathrm{s}}}{H_{\mathrm{s}}}\right)$

where, $P_{\mathrm{o}}$ is the uniform pressure on geotextile $(\mathrm{kPa}), \sigma_{\mathrm{s}}$ is the pressure of soft soil ground midway between the pile heads $(\mathrm{kPa}), \Delta$ is the mid span deflection of earth platform $(\mathrm{mm}), E_{\mathrm{s}}$ is the Young's modulus of soft soil $(\mathrm{kPa}), H_{\mathrm{s}}$ is the Original thickness of soft soil (mm).

Based on the proposed formula, by disregarding the value of $P_{\mathrm{o}}$ (since the analysis is devoid of geotextile) the equation can be simplified as follows: 
Table 6 Deflection of earth platform and vertical stress on soft soil ground midway

\begin{tabular}{|c|c|c|c|c|c|c|}
\hline & & & $S$ & SL & SLF & SLCF \\
\hline Young's modulus & $E_{\mathrm{s}}$ & $\mathrm{kPa}$ & 13,000 & 29,000 & 39,000 & 51,000 \\
\hline EP mid span settlement & $\Delta$ & $\mathrm{mm}$ & 23.7 & 21.2 & 20 & 19.5 \\
\hline Vertical stress & $\sigma_{\mathrm{s}}$ & $\mathrm{kPa}$ & 15 & 14.8 & 12.6 & 12.3 \\
\hline
\end{tabular}

$\sigma_{\mathrm{s}}=\frac{E_{\mathrm{s}}}{H_{\mathrm{s}}}$

As can be seen from Table 6, the higher Young's modulus EP has the lower mid span deflection of EP. Thus, the pressure contact between the EP and soft soil will be lower; therefore the stress on soft soil becomes lower. From this phenomenon, it can be observed that the Young's modulus of the EP has a great influence in reducing EP mid-span settlement as well reducing stress on soft soil as a result of the respectable bending performance of the treated earth platform.

\section{Conclusions}

This laboratory investigation and numerical analysis-based investigation explored the effects of treated coir fibre and lime on the mechanical performance of the treated soil as a pile-supported load-transfer platform. The following conclusions can be drawn from this study:

- Treated fibre-reinforced limed soil has better performance and can be proposed as a pile-supported loadtransfer earth platform. The presence of the proposed soil treatment leads to reduced differential settlement of the earth platform under surcharge load.

- Results of differential settlement from numerical results show good agreement with experimental results, therefore the numerical model can be used for parametric study to observe the effect of various soil properties on vertical stress, efficacy and differential settlement.

- The numerical analyses showed the importance of the strength properties of the treated soils on the efficacy. Also, the internal friction angle and cohesion influenced the load transfer onto the piles and the settlement reduction.

- The other advantage of using soil reinforcement in an earth platform is the improvement of the bending performance of earth platform against flexural stress.

Acknowledgments The Financial support from the Research Management Center (RMC) of the Universiti Putra Malaysia under RUGS (No. 9346000) "Development and optimisation of using treated coir fibre and lime as earth platform in soft soil" is gratefully acknowledged.

\section{References}

1. Briançon L, Kastner R, Simon B, Dias D (2004) Etat des connaissances-Amélioration des sols par inclusions rigides. In: Proceedings international symposium on ground improvement (ASEP-GI 2004), Paris, France

2. Okyay U, Dias D, Thorel L, Rault G (2013) Centrifuge modeling of a pile-supported granular earth-platform. J Geotech Geoenviron Eng 140(2):04013015

3. Abusharar SW, Zheng J-J, Chen B-G, Yin J-H (2009) A simplified method for analysis of a piled embankment reinforced with geosynthetics. Geotext Geomembr 27(1):39-52

4. Hewlett W, Randolph M (1988) Analysis of piled embankments. Int J Rock Mech Min Sci Geomech Abstr Elsevier Sci 25(6):297-298

5. Low B, Tang S, Choa V (1994) Arching in piled embankments. J Geotech Eng 120(11):1917-1938

6. Okyay U, Dias D (2010) Use of lime and cement treated soils as pile supported load transfer platform. Eng Geol 114(1):34-44

7. Van Eekelen SJ, Bezuijen A, Van Tol A (2011) Analysis and modification of the British Standard BS8006 for the design of piled embankments. Geotext Geomembr 29(3):345-359

8. Ziegler S, Leshchinsky D, Ling HI, Perry EB (1998) Effect of short polymeric fibers on crack development in clays. Soils Found 38(1):247-253

9. Divya P, Viswanadham B, Gourc J (2014) Evaluation of tensile strength-strain characteristics of fiber-reinforced soil through laboratory tests. J Mater Civ Eng 26(1):14-23

10. Viswanadham B, Jha B, Pawar S (2010) Influence of geofibers on the flexural behavior of compacted soil beams. Geosynth Int 17(2):86-99

11. Anggraini V, Asadi A, Huat BBK, Nahazanan H (2015) Effects of coir fibers on tensile and compressive strength of lime treated soft soil. Measurement 59:372-381

12. Maher M, Ho Y (1994) Mechanical properties of kaolinite/fiber soil composite. J Geotech Eng 120(8):1381-1393

13. Fatahi B, Le TM, Fatahi B, Khabbaz H (2013) Shrinkage properties of soft clay treated with cement and geofibers. Geotech Geol Eng 31(5):1421-1435

14. Cai Y, Shi B, Ng CW, Tang C-s (2006) Effect of polypropylene fibre and lime admixture on engineering properties of clayey soil. Eng Geol 87(3):230-240

15. Tang C, Shi B, Gao W, Chen F, Cai Y (2007) Strength and mechanical behavior of short polypropylene fiber reinforced and cement stabilized clayey soil. Geotext Geomembr 25(3):194-202

16. Fatahi B, Khabbaz H, Fatahi B (2012) Mechanical characteristics of soft clay treated with fibre and cement. Geosynth Int 19(3):252-262

17. Sivakumar Babu G, Vasudevan A, Sayida M (2008) Use of coir fibers for improving the engineering properties of expansive soils. J Nat Fibers 5(1):61-75

18. Ayyar Ramanatha T, Nair R, Nair B (2002) Comprehensive reference book on coir geotextiles. Centre for Development of Coir Technology (C-DOCT), Trivandrum

19. Dutta R, Khatri VN, Venkataraman G (2012) Effect of addition of treated coir fibres on the compression behaviour of clay. J Civ Eng (IEB) 40(2):203-214 
20. Silva GG, De Souza D, Machado J, Hourston D (2000) Mechanical and thermal characterization of native Brazilian coir fiber. J Appl Polym Sci 76(7):1197-1206

21. Marques AR, Santiago de Oliveira Patrício P, Soares dos Santos F, Monteiro ML, de Carvalho Urashima D, de Souza Rodrigues C (2014) Effects of the climatic conditions of the southeastern Brazil on degradation the fibers of coir-geotextile: evaluation of mechanical and structural properties. Geotext Geomembr 42(1):76-82

22. Khalil HSA, Alwani MS, Omar AKM (2007) Chemical composition, anatomy, lignin distribution, and cell wall structure of Malaysian plant waste fibers. BioResources 1(2):220-232

23. John V, Cincotto M, Sjöström C, Agopyan V, Oliveira C (2005) Durability of slag mortar reinforced with coconut fibre. Cement Concr Compos 27(5):565-574

24. Asasutjarit C, Charoenvai S, Hirunlabh J, Khedari J (2009) Materials and mechanical properties of pretreated coir-based green composites. Compos B Eng 40(7):633-637

25. Ardanuy M, Claramunt J, Toledo Filho RD (2015) Cellulosic fiber reinforced cement-based composites: a review of recent research. Constr Build Mater 79:115-128

26. Jenk O, Dias D, Kastner R (2007) Two-dimensional physical and numerical modeling of a pile-supported earth platform over soft soil. J Geotech Geoenviron Eng 133(3):295-305

27. Han J, Gabr M (2002) Numerical analysis of geosynthetic-reinforced and pile-supported earth platforms over soft soil. J Geotech Geoenviron Eng 128(1):44-53
28. Jenck O, Dias D, Kastner R (2009) Three-dimensional numerical modeling of a piled embankment. Int J Geomech 9(3):102-112

29. Nguyen TL, Reiffsteck P (2008) Comparaison des paramètres d'élasticité anisotrope de l'argile naturelle de Cubzac-les-Ponts déterminés à partir de différentes techniques au laboratoire. XXIVe Rencontres Universitaires de Génie Civil., Nancy 4

30. Guido V, Knueppel J, Sweeny M (1987) Plate loading tests on geogrid-reinforced earth slabs. In: Geosynthetic'87 conference

31. Rogbeck Y, Gustavsson S, Sodergren I, Lindquist D (1998) Reinforced piled embankments in Sweden-design aspects. In: Proceedings of the sixth international conference on geosynthetics

32. Russell D, Pierpoint N (1997) An assessment of design methods for piled embankments. Ground Eng 30(10):39-44

33. Terzaghi K, Terzaghi K, Engineer C, Czechoslowakia A, Terzaghi K, Civil I, Tchécoslovaquie A, Unis E (1943) Theoretical soil mechanics, vol 18 . Wiley, New York

34. Nguyen LD, Fatahi B, Khabbaz H (2014) A constitutive model for cemented clays capturing cementation degradation. Int J Plast $56: 1-18$

35. Dano C, Hicher P-Y, Tailliez S (2004) Engineering properties of grouted sands. J Geotech Geoenviron Eng 130(3):328-338

36. Jenck O, Dias D, Kastner R (2005) Soft ground improvement by vertical rigid piles two-dimensional physical modelling and comparison with current design methods. Soils Found 45(6):15-30 